\title{
Dopamine secreting adrenal tumor-ganglioneuroma rather than pheochromocytoma: case report
}

\author{
Alicia J. Burns ${ }^{1}$, Kevin M. Sullivan ${ }^{2}$, Eun K. Koh ${ }^{3}$, Maria S. Tretiakova ${ }^{4} \wedge$, Nicole K. Zern ${ }^{\wedge}$ \\ ${ }^{1}$ School of Medicine, University of Washington, Seattle, WA, USA; ${ }^{2}$ Department of Surgery, University of Washington, Seattle, WA, USA; \\ ${ }^{3}$ Multicare Endocrinology, Tacoma, WA, USA; ${ }^{4}$ Department of Pathology, University of Washington, Seattle, WA, USA \\ Correspondence to: Nicole Zern, MD, FACS. Department of Surgery, University of Washington, 1959 NE Pacific Street, Box \#356410, Seattle, WA \\ 98195, USA. Email: nkzern@uw.edu.
}

\begin{abstract}
Ganglioneuromas are rare, benign, well-differentiated neural crest tumors arising in the paravertebral sympathetic chain, and are classically non-secretory and clinically asymptomatic. As the diagnosis of ganglioneuroma is based on histopathology, the clinical presentation prior to surgical excision often mirrors that of pheochromocytoma or adrenal cortical adenoma. We describe a case of an incidentally found right sided calcified adrenal mass with evidence of marked dopamine excess, suspicious for pheochromocytoma in a 70-year-old female. The patient endorsed a 6-month history of intermittent right flank pain and a 2-year history of weight loss and fatigue. She reported mild symptoms of hypomania but denied other symptoms of dopamine excess including agitation, anxiety, nausea, and vomiting. Exam revealed isolated mild hypertension. The imaging features of this mass were concerning for malignancy including the presence of macrocalcification and irregular borders. After preoperative alpha blockade, the patient underwent open right adrenalectomy and the final pathology was consistent with ganglioneuroma rather than pheochromocytoma. Following resection, the dopamine level normalized, confirming the resected right adrenal ganglioneuroma as the source of dopamine excess. This case represents a rare presentation of dopamine-secreting adrenal ganglioneuroma. This illustrates that although rare, ganglioneuroma should be included on the differential diagnosis for functional adrenal tumors.
\end{abstract}

Keywords: Adrenal tumor; case report; dopamine; ganglioneuroma; pheochromocytoma

Submitted Apr 28, 2020. Accepted for publication Nov 09, 2020.

doi: $10.21037 /$ gs-20-475

View this article at: http://dx.doi.org/10.21037/gs-20-475

\section{Introduction}

Ganglioneuromas (GN) are rare, benign, well-differentiated neoplasms that arise from the neural crest and are comprised of Schwann cells, nerve fibers, and ganglion cells $(1,2)$. They most commonly arise along the paravertebral sympathetic chain in the posterior mediastinum and retroperitoneum (3), with $20 \%$ occurring in the adrenal gland (4). Adrenal ganglioneuromas (AGN) are a rare adrenal tumor, representing less than $5 \%$ of all adrenal tumors (5). Typically, GNs and specifically AGNs are clinically asymptomatic (6). While patients may present with non-specific symptoms such as back or abdominal pain due to tumor mass effect, most AGN are diagnosed incidentally on imaging $(4,6,7)$. As with all incidental adrenal masses, hormonal workup should be performed to determine etiology of the tumor. Thorough assessment includes evaluation of metanephrine levels, screening for cortisol excess, and measurement of plasma renin activity and aldosterone concentration.

The majority of AGN are non-secretory; there are fewer

^ ORCID: Alicia J. Burns, 0000-0003-4549-6735; Kevin M. Sullivan, 0000-0001-7455-2308; Maria S. Tretiakova, 0000-0002-0819-9638; Nicole K. Zern, 0000-0002-9550-7394. 
Table 1 Hormone-secreting AGN in adult patients in the English literature

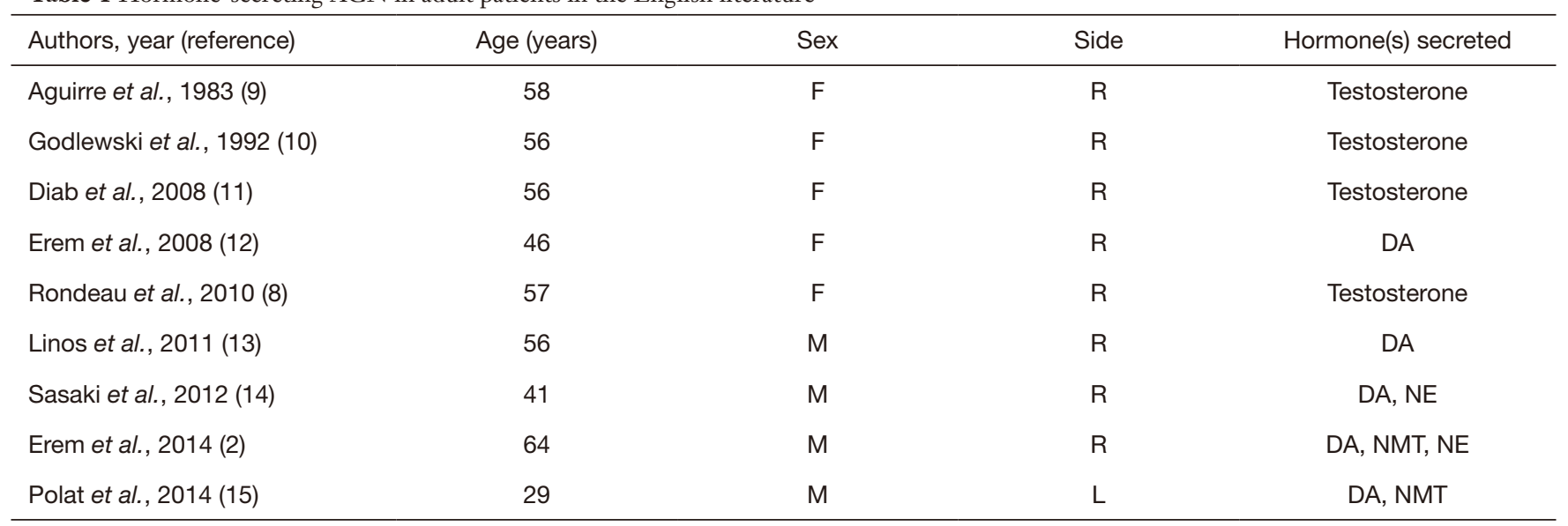

F, female; M, male; R, right; L, left; DA, dopamine; NE, norepinephrine; NMT, normetanephrine.

than 10 documented cases of pure hormone-secreting AGN in adults in English literature (8-15) (Table 1). Preoperative diagnosis of AGN is difficult due to the lack of pathognomonic findings on imaging or specific biochemical markers, thus histopathology is required for definitive diagnosis (5). In cases of AGN with hormone production, the preoperative diagnosis based on the biochemical profile will not match the histopathologic findings after surgical resection. This can result in postoperative management modifications for these patients, and an overall improvement in prognosis in many cases.

We present the following case report in accordance with the CARE reporting checklist (available at http://dx.doi. org/10.21037/gs-20-475). A timeline table of the case is included (Table 2).

\section{Case presentation}

A 70-year-old female presented to the emergency department with several days of left lower quadrant abdominal pain and was diagnosed with uncomplicated sigmoid diverticulitis. CT scan of the abdomen and pelvis with IV contrast also identified a heterogeneous partially calcified right adrenal mass measuring $7.0 \mathrm{~cm} \times 5.5 \mathrm{~cm}$ $\times 3.5 \mathrm{~cm}$ with Hounsfield Units 55-60 (Figure 1A,B). Further imaging with MRI abdomen with contrast confirmed a $7.0 \mathrm{~cm} \times 5.2 \mathrm{~cm} \times 3.5 \mathrm{~cm}$ irregularly marginated hypervascular right adrenal mass with calcification. There was no evidence of metastatic disease, and no obvious invasion into adjacent structures (Figure 1C,D).

The patient had a history of resection of a parotid myoepithelioma in 2012 but no personal history of malignancy. She had no history of treatment for hypertension or diabetes. She had no family history of adrenal or thyroid disease. The patient had symptoms of intermittent right-sided back pain for 6 months that was relieved by walking, and endorsed a 30-pound weight loss over the last 2 years accompanied by fatigue and decreased appetite. She reported possible symptoms of hypomania but denied other major symptoms of dopamine excess such as agitation, anxiety, nausea, or vomiting. The patient denied use of supplements, medications, or a dopamine diet that could account for elevations in dopamine. Physical exam was notable for a blood pressure of $138 / 97$ but was otherwise unremarkable.

A workup for functional adrenal mass was performed with blood and urine testing. Values are listed in Tables 3,4. In summary, urine dopamine was significantly elevated, and urine normetanephrine was slightly elevated above normal. The remainder of her laboratory evaluations were normal.

From the laboratory and imaging findings, the tumor was presumed to be a dopamine-secreting pheochromocytoma with suspected malignant potential. After multidisciplinary evaluation, surgical resection was recommended and the patient underwent pre-operative alpha-adrenergic blockade with doxazosin $1 \mathrm{mg}$ nightly for two weeks. She did not require beta-blockade based on the absence of rebound tachycardia in the setting of alpha blockade. The patient underwent an open right adrenalectomy under general anesthesia via a right subcostal incision. The right adrenal mass had no invasion into the liver or kidney, but was densely adherent to the posterolateral vena cava, which 
Table 2 Timeline table of case report*

\begin{tabular}{|c|c|c|c|}
\hline Dates & Summaries from initial and follow-up visits & Diagnostic testing & Interventions \\
\hline $12 / 10 / 19$ & $\begin{array}{l}\text { Admission to hospital for open right adrenalectomy } \\
\text { - Uncomplicated operation } \\
\text { - Patient required vasopressor support }<24 \text { hours } \\
\text { post-op } \\
\text { - Discharged on } 12 / 14 / 19\end{array}$ & $\begin{array}{l}\text { Surgical pathology (12/12/19): adrenal } \\
\text { ganglioneuroma }\end{array}$ & Open right adrenalectomy \\
\hline $1 / 7 / 20$ & $\begin{array}{l}\text { Endocrinology/surgery office follow-up } \\
\text { - Tumor is benign } \\
\text { - No need for genetic testing as not a } \\
\text { pheochromocytoma }\end{array}$ & $\begin{array}{l}\text { Laboratory testing }(1 / 20): 24 \text { hours urine } \\
\text { dopamine within normal limits } \\
\text { (162 } \mathrm{\mu g} / 24 \text { hours) }\end{array}$ & $\begin{array}{l}\text { Follow-up in } 1 \text { year for repeat } \\
24 \text { hours urine dopamine } \\
\text { testing }\end{array}$ \\
\hline
\end{tabular}

*, dates: year 2012; relevant past medical history and interventions: resection of parotid myoepithelioma.

required meticulous dissection in this area to free it from the vessel. She had no profound hemodynamic fluctuation during the operation but did require vasopressor support for less than 24 hours post-operation. Once hemodynamics improved with fluid resuscitation and vasopressors were weaned off, the remainder of her hospital course was uncomplicated and she was discharged to home on postoperative day 5 .

Gross examination of the adrenal gland revealed an irregular mass measuring $6.5 \mathrm{~cm} \times 4.8 \mathrm{~cm} \times 4.2 \mathrm{~cm}$ with yellow-tan to red myxoid cut surface that surrounded a large central area of dense calcification (Figure 2A). On microscopic examination the multinodular tumor with whorled appearance was pushing into adrenal parenchyma with areas of sharp demarcation as well as insinuating between nests of normal adrenocortical cells (Figure 2B,C). The histologic features included characteristic ganglioneuroma mixture of abundant spindle-cell matrix of Schwann cells, nerve fibers and mature ganglion cells. Some areas demonstrated prominent tumor hyalinization, calcification, lymphoplasmacytic infiltrates and myxoid degeneration (Figure 2D,E), but no necrosis, atypia or mitotic activity. Mature ganglion cells had typical cytology with abundant eosinophilic cytoplasm, eccentric large nuclei with prominent nucleoli, variable amounts of Nissl substance, coarse brown and black pigment consistent with lipofuscin and neuromelanin (Figure 2F). There were no morphologic features of pheochromocytoma component/ composite tumor in all examined sections.

In follow up, the pathology findings were discussed with the patient in that she had a ganglioneuroma rather than a pheochromocytoma as diagnosed preoperatively. This modified her postoperative plan so that she no longer required genetic analysis, and she received a benign 

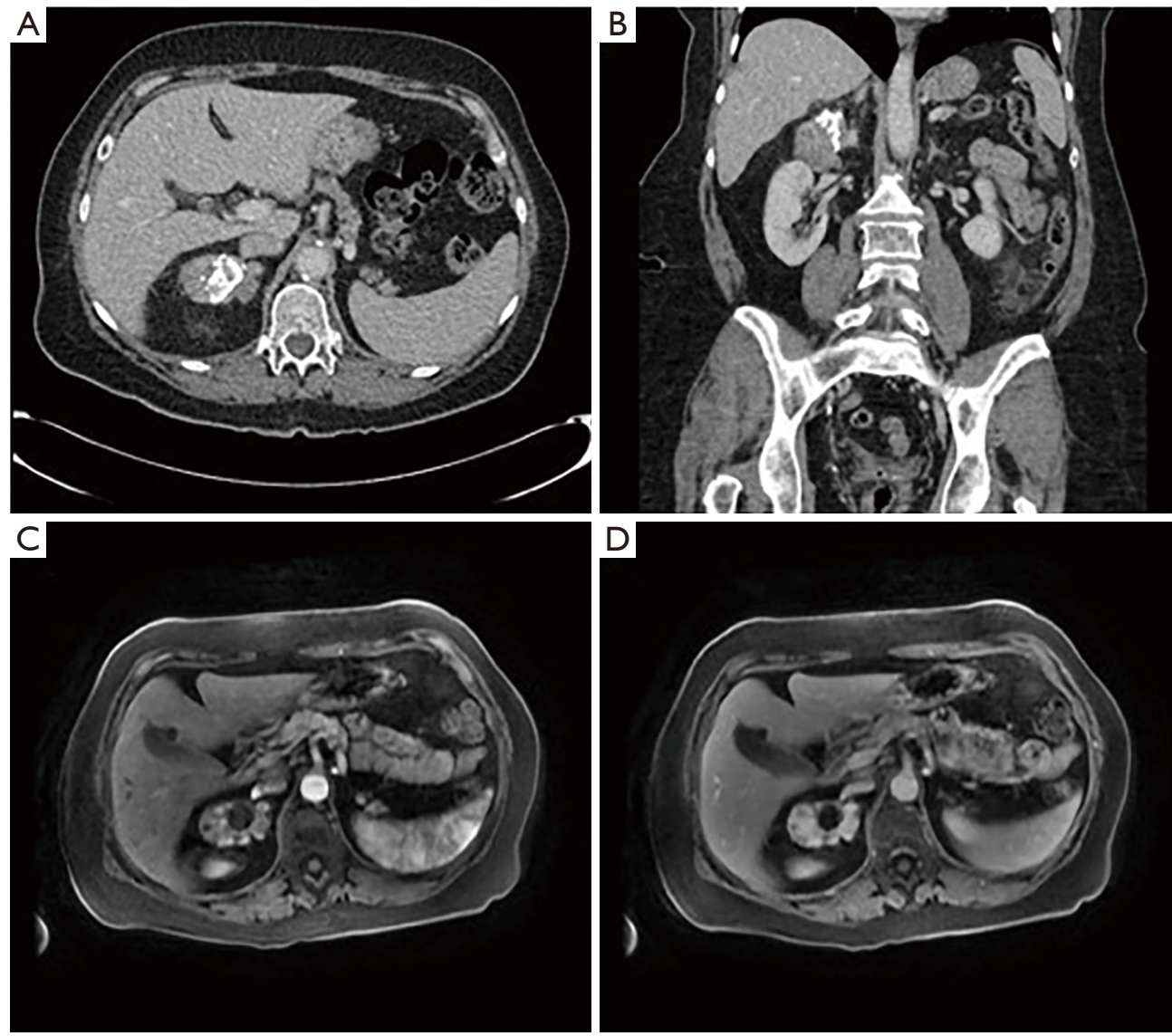

Figure 1 Cross sectional imaging of right adrenal. CT abdomen with IV contrast in the axial (A) and coronal (B) planes demonstrates an irregular right adrenal mass measuring $3.5 \mathrm{~cm} \times 5.5 \mathrm{~cm} \times 7.0 \mathrm{~cm}$ mass with calcifications present. MRI imaging of the early (C) and late (D) contrast phases also shows irregular right adrenal mass.

Table 3 Preoperative adrenal hormone evaluations

\begin{tabular}{lll}
\hline Laboratory test & Value & Reference range \\
\hline 24 hours urine dopamine & $1,922 \mu \mathrm{g} / 24$ hours & $65-400 \mu \mathrm{g} / 24 \mathrm{hours}$ \\
24 hours urine epinephrine & $2.0 \mu \mathrm{g} / 24 \mathrm{hours}$ & $<21 \mu \mathrm{g} / 24 \mathrm{hours}$ \\
24 hours urine norepinephrine & $58 \mu \mathrm{g} / 24 \mathrm{hours}$ & $15-80 \mu \mathrm{g} / 24 \mathrm{hours}$ \\
24 hours urine metanephrine & $84 \mu \mathrm{g} / 24 \mathrm{hours}$ & $30-180 \mu \mathrm{g} / 24 \mathrm{hours}$ \\
24 hours urine normetanephrine & $611 \mu \mathrm{g} / 24 \mathrm{hours}$ & $148-560 \mu \mathrm{g} / 24 \mathrm{hours}$ \\
24 hours urine cortisol & $2.5 \mu \mathrm{g} / 24 \mathrm{hours}$ & $<45 \mu \mathrm{g} / 24 \mathrm{hours}$ \\
Plasma metanephrine & $<0.20 \mathrm{nmol} / \mathrm{L}$ & $<0.50 \mathrm{nmol} / \mathrm{L}$ \\
Plasma normetanephrine & $0.85 \mathrm{nmol} / \mathrm{L}$ & $<0.90 \mathrm{nmol} / \mathrm{L}$ \\
Plasma aldosterone & $9.4 \mathrm{ng} / \mathrm{dL}$ & $<21 \mathrm{ng} / \mathrm{dL}$ \\
Plasma renin & $<0.6 \mathrm{ng} / \mathrm{mL} / \mathrm{hour}$ & $<0.603 .0 \mathrm{ng} / \mathrm{mL} / \mathrm{hour}$ \\
AM cortisol level (dexamethasone suppression test) & $1.0 \mu \mathrm{g} / \mathrm{dL}$ & $<5 \mu \mathrm{dL}$ \\
\hline
\end{tabular}


Table 4 Serum chemistry and complete blood count

\begin{tabular}{|c|c|c|}
\hline Laboratory test & Value & Reference range \\
\hline Hemoglobin & $12.3 \mathrm{~g} / \mathrm{dL}$ & $12.0-16.0 \mathrm{~g} / \mathrm{dL}$ \\
\hline Platelet & $293 \mathrm{~K} / \mu \mathrm{L}$ & $150-450 \mathrm{~K} / \mu \mathrm{L}$ \\
\hline $\mathrm{Na}$ & 138 mmol/L & $135-145 \mathrm{mmol} / \mathrm{L}$ \\
\hline $\mathrm{Cl}$ & $99 \mathrm{mmol} / \mathrm{L}$ & 98-109 mmol/L \\
\hline $\mathrm{CO}_{2}$ & $29 \mathrm{mmol} / \mathrm{L}$ & $21-28 \mathrm{mmol} / \mathrm{L}$ \\
\hline BUN & $17 \mathrm{mg} / \mathrm{dL}$ & $8-24 \mathrm{mg} / \mathrm{dL}$ \\
\hline Creatinine & $0.71 \mathrm{mg} / \mathrm{dL}$ & $0.6-1.2 \mathrm{mg} / \mathrm{dL}$ \\
\hline ALT & 17 IU/L & 6-60 IU/L \\
\hline Alk phos & $84 \mathrm{IU} / \mathrm{L}$ & 28-126 IU/L \\
\hline Total bilirubin & $0.4 \mathrm{mg} / \mathrm{dL}$ & $0.2-1.4 \mathrm{mg} / \mathrm{dL}$ \\
\hline Albumin & $4.1 \mathrm{~g} / \mathrm{dL}$ & $2.0-4.5 \mathrm{~g} / \mathrm{dL}$ \\
\hline
\end{tabular}

pathology report. Repeat 24-hour urine dopamine level one month after the operation was $162 \mathrm{mcg} / 24$ hours, within normal limits.

All procedures performed in studies involving human participants were in accordance with the ethical standards of the institutional and/or national research committee(s) and with the Helsinki Declaration (as revised in 2013). Written informed consent was obtained from the patient for publication of this case report and any accompanying images. A copy of the written consent is available for review by the Editor-in-Chief of this journal. Our patient reported the following about her experience: "Recovery was quick and pretty easy for me. The main thing I noticed is that having more balanced adrenal hormones is beneficial. I feel much more energetic and well. The joint issues of the last few years have not shown up either... so I am grateful to be "me" again."

\section{Discussion}

We present a case of a large right adrenal mass initially suspicious for a dopamine-secreting pheochromocytoma with malignant potential based on cross sectional imaging and laboratory studies. However, final pathology revealed a ganglioneuroma arising from the adrenal gland, and the post-operative normalization of urine dopamine confirmed a dopamine-secreting AGN.

GN are a benign neoplasm in the family of neurogenic tumors that includes neuroblastoma (malignant) and ganglioneuroblastoma (intermediate malignant potential) $(1,5,16)$. GN can arise anywhere along the sympathetic chain and most commonly involve the posterior mediastinum (39-43\%) and the retroperitoneum $(32-52 \%)(17)$. They are less commonly found in the adrenal medulla (21\%) (4). GN are most commonly not hormonally productive and therefore clinically asymptomatic despite large tumor size, on average $5-7 \mathrm{~cm}$ $(1,3-8)$. Catecholamine secretion will be observed if the GN is a composite tumor with a pheochromocytoma. Additionally, although rare, hormone-secreting pure GN in adults have been reported and can demonstrate secretion of testosterone, dopamine or norepinephrine (Table 1).

AGN are a rare finding on adrenal gland histopathology. The incidence of AGN in patients who have undergone adrenalectomy is $0.3 \%$ to $2.0 \%$ (4). On review of the literature, pure AGN is present more in females and has a right-sided predominance, as seen in our patient (Table 1). AGN has been reported to adhere to surrounding large vascular structures, such as the inferior vena cava, which was also seen intraoperatively with our case. AGN are thought to develop in childhood, but the average age of presentation 

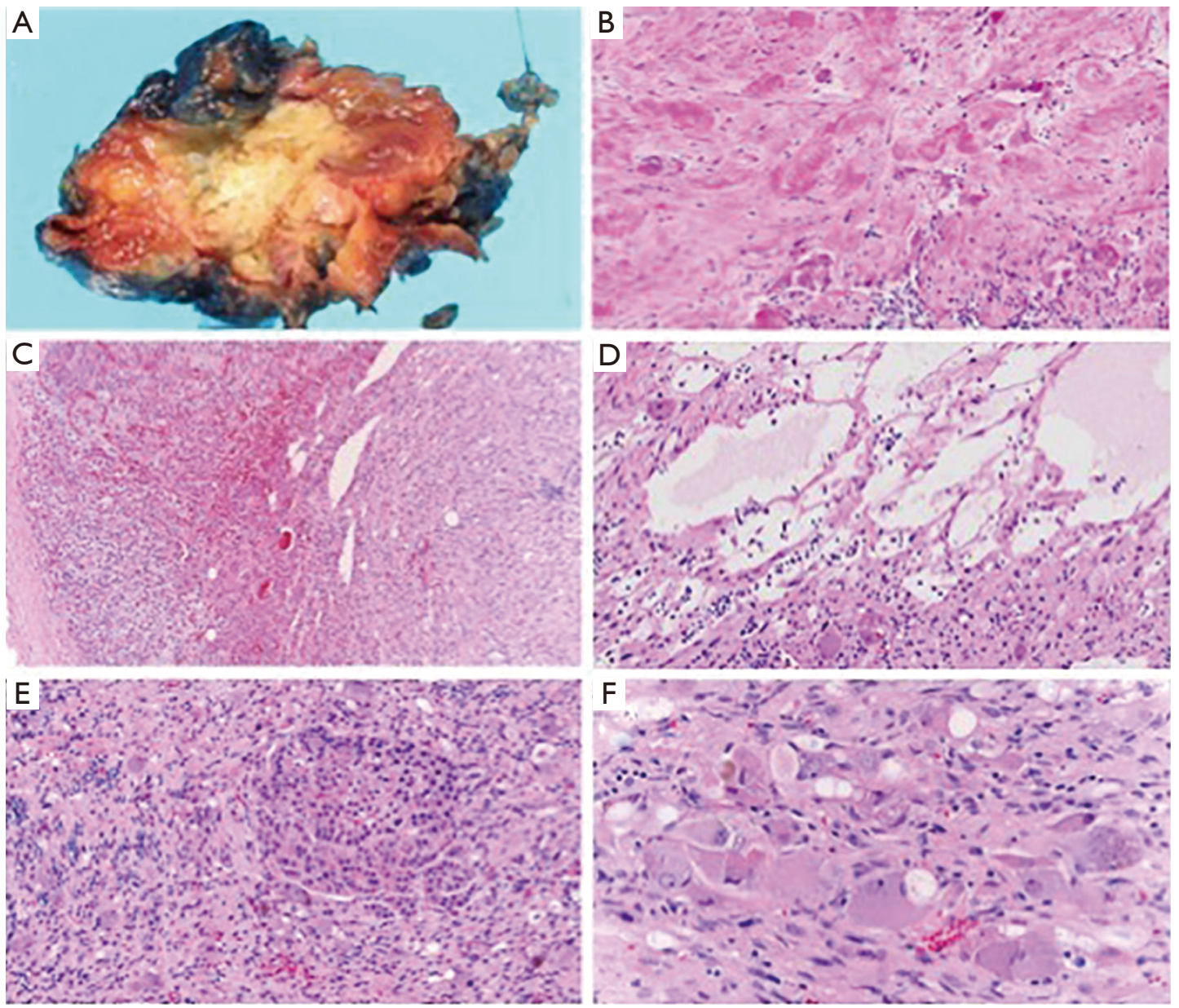

Figure 2 Adrenal ganglioneuroma Histopathology. (A) gross image of adrenal grand with irregular yellow soft tumor with areas of calcification and myxoid degeneration. (B) Overview image with interface between adrenal cortex (left) and ganglioneuroma composed of ganglion cells, abundant Schwannian-like spindle cells arranged in fascicles and nerve fibers (right) $(\times 100)$. (C) Nests of adrenocortical cells embedded into the ganglioneuroma $(\times 200)$. (D) Area of dense collagen, hyalinization, and calcification with scattered degenerating ganglion cells $(\times 200)$. (E) Area of cystic and myxoid change $(\times 200)$. (F) The ganglion cells with large eosinophilic cytoplasm, peripheral vesicular nuclei with prominent nucleoli and variable amounts of pigment consistent with lipofuscin and neuromelanin $(\times 400)$.

is between the 4th and 5 th decade due to their indolent nature (5). There are some features on CT and MRI that are characteristic of AGN including late contrast enhancement and occasional calcifications, however these features are not specific for AGN $(1,4-7,16)$. Given the lack of pathognomonic features for AGN on imaging, it is difficult to diagnose preoperatively and requires histopathology for definitive diagnosis. Given that the majority of AGN are hormonally silent, there are less than 10 documented cases of hormone-secreting pure AGN in adults (Table 1). Our case illustrates the third case of dopamine excess without the presence of a concurrent pheochromocytoma.

\section{Conclusions}

Adrenal ganglioneuroma is a rare, benign, typically nonfunctional tumor diagnosed by histopathology after surgical resection. Given neural crest origin of these tumors, rare cases can demonstrate hormone secretion and thus mimic pheochromocytoma preoperatively. We report the third case in the literature of a purely dopamine secreting adrenal ganglioneuroma.

\section{Acknowledgments}

Funding: None. 


\section{Footnote}

Reporting Checklist: The authors have completed the CARE reporting checklist. Available at http://dx.doi.org/10.21037/ gs-20-475

Peer Review File: Available at http://dx.doi.org/10.21037/gs$20-475$

Conflicts of Interest: All authors have completed the ICMJE uniform disclosure form (available at http://dx.doi. org/10.21037/gs-20-475). The authors have no conflicts of interest to declare.

Ethical Statement: The authors are accountable for all aspects of the work in ensuring that questions related to the accuracy or integrity of any part of the work are appropriately investigated and resolved. All procedures performed in studies involving human participants were in accordance with the ethical standards of the institutional and/or national research committee(s) and with the Helsinki Declaration (as revised in 2013). Written informed consent was obtained from the patient for publication of this case report and any accompanying images.

Open Access Statement: This is an Open Access article distributed in accordance with the Creative Commons Attribution-NonCommercial-NoDerivs 4.0 International License (CC BY-NC-ND 4.0), which permits the noncommercial replication and distribution of the article with the strict proviso that no changes or edits are made and the original work is properly cited (including links to both the formal publication through the relevant DOI and the license). See: https://creativecommons.org/licenses/by-nc-nd/4.0/.

\section{References}

1. Rha SE, Byun JY, Jung SE, et al. Neurogenic tumors in the abdomen: tumor types and imaging characteristics. Radiographics 2003;23:29-43.

2. Erem C, Fidan M, Civan N, et al. Hormone-secreting large adrenal ganglioneuroma in an adult patient: A case report and review of literature. Blood Press 2014;23:64-9.

3. Erem C, Ucuncu O, Nuhoglu I, et al. Adrenal ganglioneuroma: report of a new case. Endocrine 2009;35:293-6.

4. Lee JH, Chai YJ, Kim TH, et al. Clinicopathological Features of Ganglioneuroma Originating From the Adrenal Glands. World J Surg 2016;40:2970-5.
5. Iacobone $M$, Torresan F, Citton M, et al. Adrenal ganglioneuroma: the Padua endocrine surgery unit experience. Int J Surg 2017;41 Suppl 1:S103-8.

6. Shawa H, Elsayes KM, Javadi S, et al. Adrenal ganglioneuroma: features and outcomes of 27 cases at a referral cancer centre. Clin Endocrinol (Oxf) 2014;80:342-7.

7. Xie J, Dai J, Zhou WL, et al. Adrenal ganglioneuroma: features and outcomes of 42 cases in a Chinese population. World J Surg 2018;42:2469-75.

8. Rondeau G, Nolet S, Latour M, et al. Clinical and biochemical features of seven adult adrenal ganglioneuromas. J Clin Endocrinol Metab 2010;95:3118-25.

9. Aguirre P, Scully RE. Testosterone-secreting adrenal ganglioneuroma containing Leydig cells. Am J Surg Pathol 1983;7:699-705.

10. Godlewski G, Nguyen Trong AH, Tang J, et al. Virilizing adrenal ganglioneuroma containing Leydig cells. Acta Chir Belg 1993;93:181-4.

11. Diab DL, Faiman C, Siperstein AE, et al. Virilizing adrenal ganglioneuroma in a woman with subclinical Cushing syndrome. Endocr Pract 2008;14:584-7.

12. Erem C, Kocak M, Cinel A, et al. Dopamine secreting adrenal ganglioneuroma presenting with paroxysmal hypertension attacks. Saudi Med J 2008;29:122-5.

13. Linos D, Tsirlis T, Kapralou A, et al. Adrenal ganglioneuromas: incidentalomas with misleading clinical and imaging features. Surgery 2011;149:99-105.

14. Sasaki S, Yasuda T, Kaneto H, et al. Large adrenal ganglioneuroma. Intern Med 2012;51:2365-70.

15. Polat AV, Polat AK, Aslan K, et al. Dopamine-secreting giant adrenal ganglioneuroma: clinical and diffusionweighted magnetic resonance imaging findings. JBR-BTR 2014;97:109-12.

16. Adas M, Koc B, Adas G, et al. Ganglioneuroma presenting as an adrenal incidentaloma: a case report. J Med Case Rep 2014;8:131.

17. Zhou I, Liang Q, Ou WT, et al. Laparoscopic resection of primary adrenal ganglioneuroma: a case report and review of the literature. Oncol Lett 2015;9:2167-70.

Cite this article as: Burns AJ, Sullivan KM, Koh EK, Tretiakova MS, Zern NK. Dopamine secreting adrenal tumorganglioneuroma rather than pheochromocytoma: case report. Gland Surg 2020;9(6):2204-2210. doi: 10.21037/gs-20-475 